\title{
Changes in the plasma free amino acid profile of the Norway lobster Nephrops norvegicus at different stages of infection by a parasitic dinoflagellate (genus Hematodinium)
}

\author{
G. D. Stentiford ${ }^{1, *}$, D. M. Neil ${ }^{1}$, G. H. Coombs ${ }^{2}$ \\ ${ }^{1}$ Division of Environmental \& Evolutionary Biology, Graham Kerr Building, University of Glasgow, Glasgow G12 8QQ, \\ Scotland, UK \\ ${ }^{2}$ Laboratory for Biochemical Parasitology, Division of Infection \& Immunity, University of Glasgow, Glasgow G12 8QQ, \\ Scotland, UK
}

\begin{abstract}
The haemolymph free amino acid (FAA) composition of Norway lobsters Nephrops norvegicus from the Clyde estuary, Scotland, UK, at different stages of infection by the parasitic dinoflagellate Hematodinium sp. was determined by reverse phase high performance liquid chromatography (HPLC). In uninfected lobsters the total detected haemolymph FAA concentration was $3.79 \mu \mathrm{mol} \mathrm{ml}^{-1}$. Collectively, glycine, histidine/glutamine, alanine, serine, taurine and asparagine constituted $80 \%$ of the total. The concentrations of several FAAs, notably serine, were reduced in early infections (Stage 1), while at later stages (2-4) several FAAs were increased in concentration. The most significant change was in taurine, which had increased 13 -fold (from 0.22 to $2.56 \mu \mathrm{mol} \mathrm{m}^{-1}$ ) in the final infection stage, when its relative contribution to the total FAA was $41.6 \%$. Possible causes of these changes in the lobster haemolymph FAAs are the breakdown of host tissues including the hepatopancreas and muscle, haemocyte lysis, a host stress response and release of FAAs from the parasite cells. Results indicate that the taurine:serine ratio in the haemolymph provides a sensitive diagnostic measure of patent Hematodinium infections. Implications of these FAA alterations for Hematodinium-infected N. norvegicus are discussed.
\end{abstract}

KEY WORDS: Nephrops norvegicus $\cdot$ Haemolymph $\cdot$ Free amino acids Taurine $\cdot$ Hematodinium

\section{INTRODUCTION}

One consequence of some parasitic infections of invertebrates is change to the free amino acid (FAA) profile in the plasma. This occurs in oysters infected by Bucephalus sp. and Minchinia nelsoni (Feng et al. 1970), honey bees infected by the microsporidian Nosema apis (Wang \& Moeller 1970), and mosquitoes infected with Nosema algerae (Henn et al. 1998). There have been very few such studies on parasitized crustaceans, although alterations to the plasma FAA profile have been reported for the bacterium Aerococ-

\footnotetext{
•E-mail: g.stentiford@udcf.gla.ac.uk
}

cus viridans infection in lobsters (Stewart 1980) and the microsporidia Thelohania maenadis and Ameson michaelis infections in crabs (Vivares et al. 1980, Findley et al. 1981).

Populations of the Norway lobster Nephrops norvegicus from the coastal waters off the west coast of Scotland are infected with the dinoflagellate Hematodinium sp., with overall prevalence levels of over $70 \%$ in some years (Field et al. 1992). The parasite is systemic, invading most major tissues and organs, causes considerable histological disruption (Field \& Appleton 1995) and has a major effect on the appearance and properties of the haemolymph, including extensive loss of normal haemocytes (Taylor et al. 1996). However, there are no reports on the biochemical conse- 
quences of the infection. $N$. norvegicus is typical of marine crustaceans in having a large intracellular FAA pool (Robertson 1961, Robertson et al. 1992), while extracellular concentrations are low. With such high tissue:haemolymph FAA ratios, the extensive pathological effects of Hematodinium infection on the tissues and organs of $N$. norvegicus may be expected to cause increases in the haemolymph concentrations of amino acids when released from damaged cells. There may also be compensation for the parasite-induced changes to the haemolymph.

Therefore this project was undertaken to determine the haemolymph FAA composition during infection of Nephrops norvegicus by Hematodinium, to elucidate the extent of such changes, to chart their time course in relation to the onset and progress of the infection, and to determine whether the host undergoes compensatory changes in its plasma FAA profile.

\section{METHODS}

Collection and treatment of lobsters. Norway lobsters Nephrops norvegicus were otter-trawled from a location south of Little Cumbrae in the Clyde Sea area, Scotland, UK, and subsequently maintained in a closed aquarium $\left(10^{\circ} \mathrm{C}, 33 \mathrm{ppt}\right.$ salinity $)$ in the Division of Environmental and Evolutionary Biology, University of Glasgow, Scotland, UK. Experimental lobsters were fed ad libitum, once weekly on mussels Mytilus edulis but were not fed for at least $5 \mathrm{~d}$ prior to haemolymph collection. All lobsters were in the intermoult state (Aiken 1980) and were assessed for Hematodinium infection by the pleopod staging method of Field \& Appleton (1995).

Sample collection. Haemolymph was drawn from the base of the fifth pereiopod into a sterile syringe and centrifuged immediately at $17000 \times g$ for $10 \mathrm{~min}$ at $10^{\circ} \mathrm{C}$ to remove cellular material and suspended debris. The clear plasma was deproteinized using ice cold methanol ( 4 parts methanol to 1 part plasma) for $10 \mathrm{~min}$ at $4^{\circ} \mathrm{C}$. Protein precipitate was removed by centrifugation and the supernatant passed through a $0.22 \mu \mathrm{m}$ filter before storage at $-70^{\circ} \mathrm{C}$.

High performance liquid chromatography (HPLC) analysis. HPLC grade methanol $(\mathrm{MeOH})$, tetrahydrofuran (THF) and acetonitrile were obtained from $\mathrm{BDH}$ Laboratory Supplies, Leicestershire, UK. Crystalline amino acids (aspartate, glutamate, asparagine, serine, histidine, glutamine, glycine, threonine, arginine, alanine, tyrosine, valine, methionine, tryptophan, phenylalanine, isoleucine and leucine), taurine, sodium acetate, mercaptoethanol ( $\mathrm{ME}$ ) and o-phthaldialdehyde (OPT) were from Sigma-Aldrich Co. (Poole, UK). Reagent grade Millipore-filtered water was used throughout.
Deproteinized plasma samples were analysed by HPLC using a Rainin Dyn Microsorb C18 4.6×150 mm column (with Microsorb C18 guard column), a Gilson HPLC system (model 302 Pumps, model 802C manometric module, model 811 dynamic solvent mixer and model 121 fluorometer) interfaced to a computer with 712 HPLC controller software. Amino acids were eluted after pre-column OPT-derivatization using the method of Zuo \& Coombs (1995) by mixing equal volumes of plasma and OPT reagent. The method allowed for quantitation of 12 amino acids and taurine. Co-elution of valine/methionine and histidine/glutamine occurred in all runs and neither cysteine nor proline were detectable. Standard curves were constructed using an equimolar mixture of the above amino acids and taurine, and plasma concentrations were derived from these curves. Comparison of FAA concentrations in the plasma of uninfected and infected Nephrops norvegicus was performed either by 1-way analysis of variance (ANOVA) for normally distributed data, or by a Kruskal-Wallace test for non-normal distributions. Between-stage comparisons were made with a Tukey's pairwise analysis (normal distributions) and a MannWhitney test (non-normal distributions). Significance was considered to be at $\mathrm{p}<0.05$.

\section{RESULTS}

\section{Analysis of the FAA concentrations in Nephrops norvegicus plasma}

A total of 81 lobsters were examined for infection by Hematodinium sp. using the pleopod staging method of Field \& Appleton (1995). Stage 0 denotes an uninfected animal, with patent infection progressing from Stage 1 to Stage 4. Plasma FAA concentrations ( $\mu$ mol $\mathrm{ml}^{-1}$ ) were derived from peak areas on the HPLC chromatograms. The OPT-derivatized FAA compounds identified in Nephrops norvegicus plasma under different levels of infection are shown in Table 1. In uninfected $N$. norvegicus (Stage 0), the total detected FAA concentration was $3.79 \mu \mathrm{mol} \mathrm{ml} \mathrm{m}^{-1}$, with glycine, histidine/glutamine, alanine, serine, taurine and asparagine collectively constituting almost $80 \%$ of this total. The total identified FAA concentration was highest in the plasma of Stage 3 lobsters $\left(6.70 \mu \mathrm{mol} \mathrm{m}{ }^{-1}\right)$, this being significantly greater than that of uninfected plasma $(p<0.001)$.

The FAA profile of Hematodinium-infected Nephrops norvegicus plasma was substantially altered through the course of the infection (Table 1). The concentrations of 5 FAA compounds were significantly less in the plasma of Stage 1 (early patent infection) lobsters compared with uninfected controls, resulting in a depres- 
Table 1. OPT-derivatized free amino acids from the haemolymph of Nephrops norvegicus. Significant differences from Stage 0 concentrations are denoted by $\mathrm{p}<0.05, \cdots p<0.01$ and $\cdots p<0.001$. Conc: mean FAA concentration in $\mu \mathrm{mol} \mathrm{ml}^{-1} ; \pm$ SE: standard error of mean

\begin{tabular}{|c|c|c|c|c|c|c|c|c|c|c|}
\hline \multirow[t]{3}{*}{ Free amino acid } & \multicolumn{10}{|c|}{ Haemolymph free amino acid $\left(\mu \mathrm{mol} \mathrm{ml}^{-1}\right)$} \\
\hline & \multicolumn{2}{|c|}{ Stage $0(n=23)$} & \multicolumn{2}{|c|}{ Stage $1(n=11)$} & \multicolumn{2}{|c|}{ Stage $2(n=28)$} & \multicolumn{2}{|c|}{ Stage $3(n=13)$} & \multicolumn{2}{|c|}{ Stage $4(n=6)$} \\
\hline & Conc. & $\pm S E$ & Conc. & $\pm S E$ & Conc. & $\pm \mathrm{SE}$ & Conc. & $\pm \mathrm{SE}$ & Conc. & $\pm \mathrm{SE}$ \\
\hline Aspartate & 0.01 & 0.002 & 0.03 & 0.01 & 0.03 & 0.008 & 0.05 & 0.02 & 0.06 & 0.03 \\
\hline Glutamate & 0.04 & 0.007 & 0.06 & 0.01 & $0.11 \cdots$ & 0.02 & $0.19 \cdots$ & 0.03 & $0.40^{\cdots} \cdot$ & 0.21 \\
\hline Asparagine & 0.16 & 0.01 & 0.12 & 0.01 & $0.13^{\bullet}$ & 0.01 & $0.11^{\prime} \cdot$ & 0.03 & 0.09 & 0.04 \\
\hline Serine & 0.34 & 0.03 & $0.21^{\circ}$ & 0.05 & $0.17^{\cdots}$ & 0.01 & $0.18^{*}$ & 0.03 & $0.19^{\circ}$ & 0.04 \\
\hline Histidine/glutamine & 0.56 & 0.04 & $0.52 \cdots$ & 0.11 & $0.42 \cdots$ & 0.04 & $0.37^{*}$ & 0.07 & 0.44 & 0.09 \\
\hline Glycine & 1.17 & 0.15 & 0.93 & 0.17 & 1.43 & 0.14 & $1.90^{\circ}$ & 0.23 & 1.24 & 0.30 \\
\hline Threonine & 0.11 & 0.01 & 0.10 & 0.02 & 0.10 & 0.01 & 0.09 & 0.02 & 0.06 & 0.03 \\
\hline Arginine & 0.11 & 0.007 & 0.12 & 0.02 & $0.23^{\circ}$ & 0.03 & $0.31^{*}$ & 0.03 & 0.16 & 0.03 \\
\hline Alanine & 0.55 & 0.05 & 0.41 & 0.05 & 0.52 & 0.05 & 0.55 & 0.07 & 0.60 & 0.16 \\
\hline Taurine & 0.22 & 0.03 & 0.42 & 0.09 & $1.04^{\cdots}$ & 0.1 & $2.20 \cdots$ & 0.21 & $2.56^{\cdots}$ & 0.33 \\
\hline Tyrosine & 0.06 & 0.006 & 0.06 & 0.007 & 0.08 & 0.008 & $0.12^{\bullet}$ & 0.02 & 0.07 & 0.02 \\
\hline Valine/methionine & 0.14 & 0.009 & $0.10^{\circ}$ & 0.01 & 0.14 & 0.01 & 0.20 & 0.05 & 0.15 & 0.02 \\
\hline Tryptophan & 0.02 & 0.003 & $0.00^{\circ}$ & 0.00 & $0.01 \cdots$ & 0.003 & 0.03 & 0.01 & 0.02 & 0.01 \\
\hline Phenylalanine & 0.05 & 0.005 & 0.04 & 0.006 & 0.06 & 0.006 & $0.11^{\bullet}$ & 0.02 & 0.08 & 0.02 \\
\hline Isoleucine & 0.10 & 0.007 & $0.05 \cdots$ & 0.01 & 0.08 & 0.007 & 0.09 & 0.01 & 0.09 & 0.02 \\
\hline Leucine & 0.14 & 0.008 & 0.11 & 0.02 & 0.14 & 0.01 & $0.20^{\circ}$ & 0.03 & 0.20 & 0.05 \\
\hline Total identified FAA & 3.79 & 0.28 & 3.29 & 0.41 & 4.68 & 0.33 & $6.70 \cdots$ & 0.60 & $6.41^{\circ}$ & 0.93 \\
\hline
\end{tabular}

sion (though not significant) in the total concentration of detected FAA. Among the individual amino acids, the change of serine was the greatest, falling from 0.34 to $0.21 \mu \mathrm{mol} \mathrm{m} \mathrm{l}^{-1}(\mathrm{p}<0.001)$, while other FAAs showing reduced concentrations included asparagine $(\mathrm{p}<$ $0.05)$, valine-methionine $(\mathrm{p}<0.01)$, tryptophan $(\mathrm{p}<$ $0.01)$ and isoleucine $(p<0.01)$.

A different trend was apparent with lobsters at Stage 2 infection, in which several FAAs exhibited very significant increases in concentration. However, the most prominent increase was with taurine, which increased from $0.22 \mu \mathrm{mol} \mathrm{m} l^{-1}$ in Stage 0 to $1.04 \mu \mathrm{mol}$ $\mathrm{ml}^{-1}$ in Stage $2(\mathrm{p}<0.001)$. By Stage 3 of infection, taurine (at $2.20 \mu \mathrm{mol} \mathrm{ml}^{-1}$ ) was dominant in the plasma, and glutamate had also increased significantly from its Stage 2 concentration $(p<0.01)$. In contrast, serine, after its initial reduction, remained low in the later stages of infection and did not change significantly among successive levels of infection. Plasma arginine concentrations in Stage 3 lobsters were 3 times the Stage 0 levels, although the increase in total plasma FAA in Stage 3 infected lobsters was due primarily to the increased taurine concentration.

In Stage 4 lobsters, most plasma FAAs had returned to concentrations not significantly different from those of Stage 0 lobsters. The only exceptions to this were taurine, which had increased approximately 13-fold (Fig. 1a), glutamate, with a 10-fold increase (Fig. 1b), and serine, which was at approximately one-half of the concentration in uninfected lobsters (Fig. 1c).
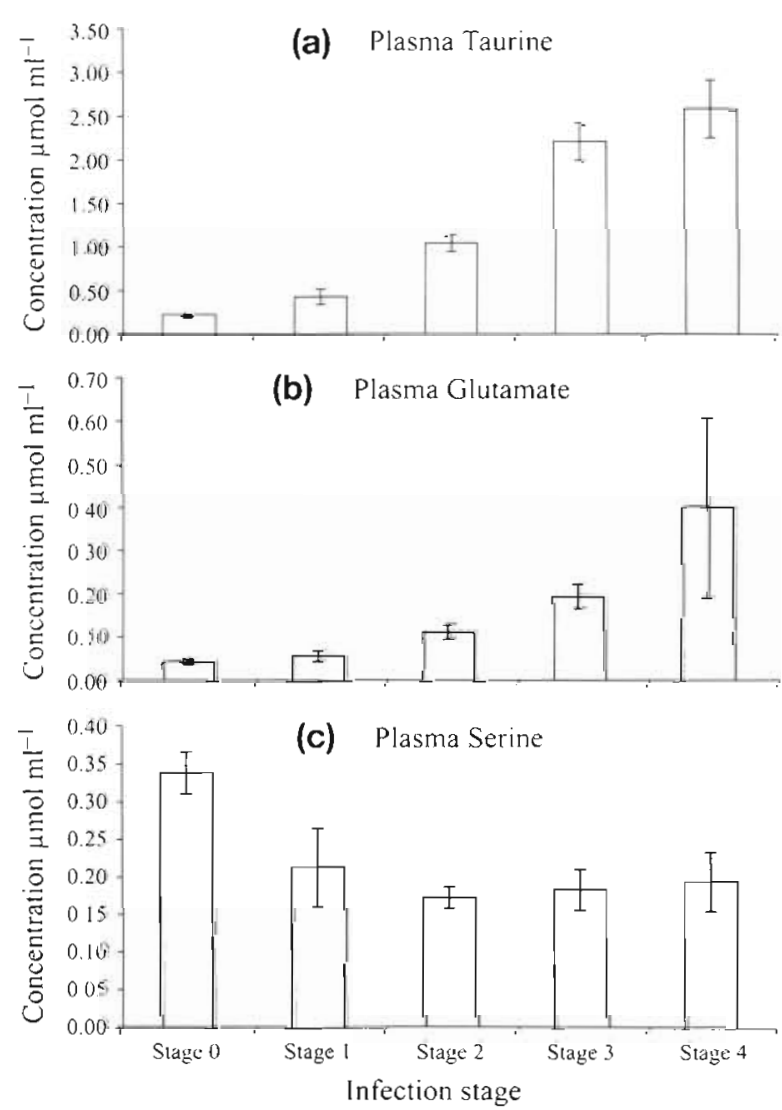

Fig. 1 Mean ( \pm SE) plasma (a) taurine, (b) glutamate and (c) serine in the haemolymph of Nephrops norvegicus at different stages of infection by Hematodinium. For statistical significance among groups see Table 1 and text 


\section{Importance of plasma taurine in infection}

Taurine accounted for the majority of the increase in total detected FAA during infection. It showed significant differences between Stages 0 and $2(p<0.001)$, 1 and $2(p<0.001)$ and 2 and 3 ( $p<0.001$ ), but not between Stages 3 and 4 ( $p>0.05$ ) (Fig. 1a). However, when expressed relative to total detected FAA concentration, the difference in taurine amounts between Stage $0(5.8 \%$ of total FAA) and Stage $1(13.7 \%$ of total FAA) are significant ( $<<0.05$ ) (Fig. 2). In addition to the absolute increase from Stage 0 to Stage $4(0.22$ to $2.56 \mu \mathrm{mol} \mathrm{ml} \mathrm{ml}^{-1}$ ), taurine also made an increasing relative contribution to total FAA, rising from $5.8 \%$ in Stage 0 to $41.6 \%$ in Stage 4 plasma. The application of a ratiometric measure of increasing taurine concentration against decreasing serine concentration (Fig. 3) also revealed significant differences between Stages 0 and 1 (i.e. between lobsters that are apparently healthy and those patently infected). The taurine:serine ratio increased significantly between Stages 0 and 1 ( $p<$ $0.01), 1$ and $2(p<0.01)$, and 2 and 3 ( $p<0.001)$, but not between Stages 3 and $4(p>0.05)$. The difference in this ratio between Stage 0 and Stage 1 is more significant $(p<0.01)$ than the comparison of absolute concentration $(p>0.05)$ or relative contribution of taurine to the total $(\mathrm{p}<0.05)$.

\section{DISCUSSION}

Several studies on invertebrates have considered alterations in FAA profile and non-protein nitrogen

\begin{tabular}{|c|c|c|c|c|}
\hline infection stage & 1 & 2 & 3 & 4 \\
\hline 0 & $\mathrm{P}<005$ & $\mathrm{P}<0001$ & $\mathrm{P}<0.001$ & $\mathrm{P}<0.001$ \\
\hline 1 & & $\mathrm{P}<0.01$ & $\mathrm{P}<0.001$ & $\mathrm{P}<0.001$ \\
\hline 2 & & $\mathrm{P}<0.001$ & $\mathrm{P}<0.001$ \\
\hline 3 & & & $\mathrm{P}>0.05$ \\
\hline
\end{tabular}

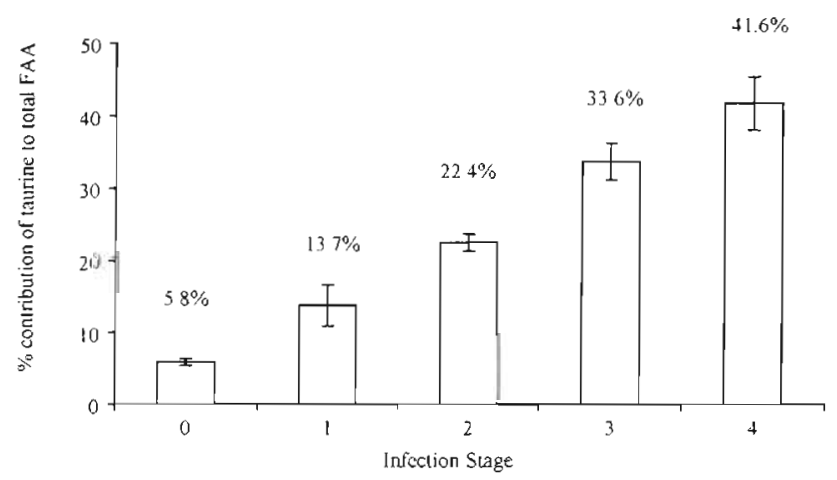

Fig. 2. Mean $( \pm \mathrm{SE})$ contribution of taurine to total detected FAA in the haemolymph of Nephrops norvegicus at different stages of infection by Hematodinium, plus between-group significant table. Mean taurine \% contributions are given above each bar

\begin{tabular}{|c|c|c|c|c|}
\hline $\begin{array}{l}\text { Infection } \\
\text { Stage }\end{array}$ & 1 & 2 & 3 & 4 \\
\hline 0 & $P<0.01$ & $P<0.001$ & $P<0.001$ & $P<0.001$ \\
\hline 1 & & $P<001$ & $P<0.001$ & $P<001$ \\
\hline 2 & & & $P<0.001$ & $P<0.01$ \\
\hline 3 & & & & $P>005$ \\
\hline
\end{tabular}

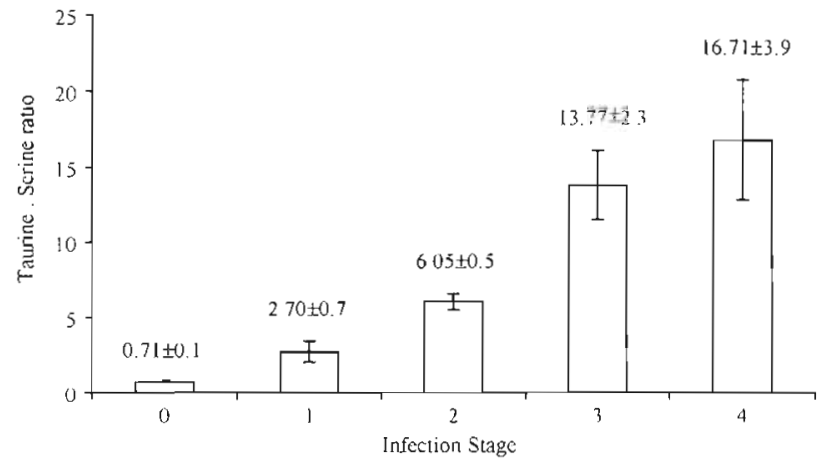

Fig. 3. Mean $( \pm S E)$ taurine:serine concentration ratios in haemolymph of Nephrops norvegicus under different degrees of infection by Hematodinium, plus between-group significance table. Mean ratio \pm standard error of mean given above each bar

under conditions of infection, but few have considered changes in the FAA profile at different stages of infection (Henn et al. 1998). The ability to estimate the infection severity by a simple morphological index applied to the host greatly facilitated the current study of Hematodinium infection in Nephrops norvegicus, allowing the changing pattern of plasma amino acid concentrations to be tracked through the course of infection. This provides a good basis for understanding the progression of biochemical disturbances that occur during Hematodinium infection.

\section{Plasma FAA profile in uninfected and infected Nephrops norvegicus}

Collectively, glycine, histidine/glutamine, alanine, serine, asparagıne and taurine constitute almost $80 \%$ of the total FAA concentration $\left(3.79 \mu \mathrm{mol} \mathrm{ml} \mathrm{m}^{-1}\right)$ in normal plasma. This compares with the total FAA concentration of $5.8 \mu \mathrm{mol} \mathrm{ml} \mathrm{ml}^{-1}$ reported for Homarus gammarus (Camien et al. 1951). It should be noted however that the data presented here for Nephrops norvegicus excludes proline, which is known to be high in the abdominal muscle of $N$. norvegicus (Robertson et al. 1992), and cysteine, both of which are not derivatized by OPT. The decrease in the concentrations of some amino acids early in infection (Table 1) is consistent with parasite utilisation of these compounds as the haemolymph is colonised. A reduction in non-protein 
nitrogen also occurs during early infection by Aerococcus viridans in Homarus americanus (Stewart 1980). The significant reduction in the concentration of free serine that occurred even in early infection (Fig. 1c) could reflect preferential utilization of this compound by Hematodinium, or alternatively parasitic consumption of carbohydrate precursors or a disruption to the biosynthetic pathway of serine. Serine is considered an intermediate in the biosynthesis of taurine in lobster skeletal muscle (Finney 1978); the observed depletion of serine may be linked to up-regulation of the synthesis of taurine during infection. Taurine is generally not metabolised, and hence the increased taurine concentration relative to total FAA (Fig. 2) could be due to a combination of increased biosynthesis and its nonutilisation relative to the other FAA compounds.

The increased total FAA concentration that occurred in later stages of infection may have several causes. There is widespread disruption in all major organs and tissues during infection of Nephrops norvegicus by Hematodinium, especially at the later stages (Field \& Appleton 1995). Intracellular compounds liberated by cellular damage would be likely to appear in the haemolymph and lead to the observed increase in concentration of total FAA. However, the elevated total FAA concentration is not due to an increase in all component FAAs, but rather to elevated levels of a few (see Table 1), which suggests either selective release or selective utilisation of released amino acids. The particular increase in plasma taurine may be due, in part, to its high concentration in the crustacean hepatopancreas (Van Marrewijk \& Ravenstein 1974) and skeletal muscle (Pochon-Masson et al. 1984), both of which undergo considerable disruption during Hematodinium infection (Field \& Appleton 1995).

Another possible source of plasma FAAs is the haemolymph itself, which contains both proteins such (predominantly haemocyanin) and various types of haemocytes. Haemolymph proteins serve as stores for amino acids (Pequeux et al. 1979), and host mobilisation or parasitic degradation of these proteins could lead to elevated levels of some FAA in the plasma. Taylor et al. (1996) reported a large reduction in plasma haemocyanin in Hematodinium sp.-infected Nephrops norvegicus. Taurine, however, is not a component of proteins, and so the elevated concentrations of this amino sulphonic acid must have a source other than the catabolism of haemocyanin. The dramatic decline in the concentration of haemocytes in the host haemolymph during severe infection (Field \& Appleton 1995) suggests that haemocytes are destroyed by the parasite (although inhibition of their production may be a contributory factor), and lysis of haemocytes would result in their cellular contents being released into the haemolymph. Taurine is concentrated within the haemocytes of certain animals (Thoroed \& Fugelli 1994). If this is the case for $N$. norvegicus, the lysis of haemocytes could also contribute to the observed elevation of the plasma taurine levels.

Since the large FAA pool in tissues of marine invertebrates is essential in osmoregulation (Claybrook 1983 Robertson et al. 1992), the increased FA.A concentration in the haemolymph of Nephrops norvegicus during late infection could, in part, reflect an attempt by the host to compensate for osmolytes depleted by the parasite, as reported for the oyster Crassostrea virginica infected by Bucephalus sp. and Minchinia nelsoni (Feng et al. 1970). Taurine is an important osmolyte in various animal groups, being a relatively more expendable amino compound as it is non-essential (Chamberlain \& Strange 1989). However, the finding that the concentration of several other amino acids not thought to be principally involved in osmoregulation also increased during Hematodinium infection (Table 1) suggests that the changes in haemolymph FAA have multiple origins

Finally, the possibility cannot be excluded that the elevated concentrations of taurine and other compounds are of parasite origin. To determine this an analysis of the FAA composition of media from in vitro cultures of Hematodinium (Appleton \& Vickerman 1998 ) and of the parasites themselves is required.

\section{Implications of plasma FAA changes to the ecology of Nephrops norvegicus}

Several studies have implicated taurine as a neurotransmitter or neuro-modulator (Kuriyama et al. 1978, Oja \& Kontro 1978). In crustaceans, taurine mimics the inhibitory actions of gamma-aminobutyric acid (GABA) and affects cardiac rhythm (Payen et al. 1981, Zatta 1987). Glutamate also has pharmacological activity at low concentrations (Lin \& Cohen 1973), and is maintained at trace concentrations $\left(0.04 \mu \mathrm{mol} \mathrm{ml}^{-1}\right)$ in the plasma of uninfected Nephrops norvegicus (Fig. 1b). However, during infection the concentration of free glutamate in $N$. norvegicus plasma increased to values that exceed the threshold for stimulating crayfish muscle $\left(0.053 \mu \mathrm{mol} \mathrm{m}^{-1}\right.$, see Lin \& Cohen 1973). Due to the open nature of the crustacean circulatory system, these elevated concentrations of neuro-active compounds could affect the behaviour and locomotory ability of Hematodinium-infected $N$. norvegicus. This could significantly alter their ability to evade capture, both by predators and by trawlers, and so has both practical and economic consequences since $N$. norvegicus is currently the United Kingdom's most valuable shellfish resource. Lobsters with late stage infections are moribund. This could result from the actions of neuroactive compounds, although the increased respiratory 
demands due to the high parasitic burden will also contribute to this state (Taylor et al. 1996).

Elevated levels of FAAs in infected plasma may also have implications for predator attraction. Amino acids play are important in prey detection in crustaceans (Voigt et al. 1996) and many species are particularly sensitive to taurine, with behavioural responses being elicited at concentrations as low as $10^{-13} \mathrm{M}$ (Johnson \& Atema 1986). The increased plasma concentration of taurine together with damage to the excretory antennal gland (Field \& Appleton 1995) implies that the excretion of taurine and other amino compounds is increased during infection. This could attract benthic scavengers which rely on chemical cues (Wong \& Moore 1995). If this is confirmed, then the possibility should be investigated that these scavenging species can act as alternative hosts for Hematodinium. This may help to elucidate the full life cycle of Hematodinium (Appleton \& Vickerman 1998).

\section{Diagnosis of Hematodinium-infection in Nephrops norvegicus}

Infection staging by examining the pleopod under low-power microscopy (Field \& Appleton 1995) is currently the primary method for field diagnosis of patent Hematodinium infection, while the use of a polyclonal antibody facilitates detection of sub-patent infections (Field \& Appleton 1996). The pleopod staging method requires laboratory facilities, is somewhat subjective and can result in mis-diagnoses of infection severity and failure to detect light infections. Another limitation is that it provides only a 'parasitic index', and not an assessment of host condition. Many studies on invertebrate responses to various stressors have suggested that the use of biochemical indices may provide more consistent and reproducible measures of host condition (Livingstone 1982, Fossi et al. 1997). The current study has shown that the taurine concentration alone can diagnose infection from Stage 2 onwards (Fig. 1a), while the reduced concentration of serine (Fig. 1c), the increased percent contribution of taurine to the total FAA (Fig. 2), and particularly the taurine:serine ratio (Fig. 3) provide powerful measures of early patent infection. The ratiometric measure also demonstrates that the distinction between Stage 3 and Stage 4 infections is an artificial one. A measure based upon the haemolymph taurine:serine ratio may be a better predictor of infection severity than the pleopod method, and could be a valuable tool for estimating disease prevalence in commercial Nephrops norvegicus stocks.

The finding of the increased concentration of taurine during Hematodinium infection of Nephrops norvegicus may also have relevance to other host-parasite interactions. As taurine is involved in stress responses and occurs at high concentrations in the tissues of many invertebrates, alterations in its plasma concentration may be both an important mediator and also a useful index in other infection pathologies and stressrelated effects.

Acknowiedgements. This work was supported by a contract from the Ministry of Agriculture Fisheries \& Food of the United Kingdom (Contract No. CSA 4172, Project code MFO221). The authors wish to thank Mr Mick Parker and the crew of the RV 'Aora' (University Marine Biological Station Millport) for assistance in collection and sorting of animals and Mr David Laughland for technical assistance and advice concerning HPLC operation.

\section{LITERATURE CITED}

Aiken DE (1980) Moulting and growth. In: Cobb JS, Phillips BF (eds) The biology and management of lobsters. Academic Press, New York, p 91-163

Appleton PL, Vickerman K (1998) In vitro cultivation and development cycle in culture of a parasitic dinoflagellate (Hematodinium sp.) associated with mortality of the Norway lobster (Nephrops norvegicus) in British waters. Parasitology 116:115-130

Camien MN, Sarlet H, Duchâteau G, Florkin M (1951) Nonprotein amino acids in muscie and blood of marine and freshwater Crustacea. J Biol Chem 193:881-885

Chamberlain ME, Strange K (1989) Aniosmotic cell volume regulation: a comparative review. Am J Physiol 277:159-173

Claybrook DL (1983) Nitrogen metabolism. In: Mantel LH (ed) The biology of Crustacea, Vol 5. Internal anatomy and physiological regulation. Academic Press, London, p 163-202

Feng SV, Khairallah EA, Canzonier WJ (1970) Hemolymph free amino acids and related nitrogenous compounds of Crassostrea virginica infected with Bucephalus sp and Minchinia nelsoni. Comp Biochem Physiol 34:547-556

Field R.H, Appleton PL (1995) A Hematodinium-like dinoflagellate infection of the Norway lobster Nephrops norvegicus: observations on pathology and progression of infection. Dis Aquat Org 22:115-128

Field RH, Appleton PL (1996) An indirect fluorescent antibody technique for the diagnosis of Hematodinium sp. infection of the Norway lobster Nephrops norvegicus. Dis Aquat Org 24:199-204

Field RH, Chapman CJ, Taylor AC, Neil DM, Vickerman K (1992) Infection of the Norway lobster Nephrops norvegicus by a Hematodinium-like species of dinoflagellate on the west coast of Scotland. Dis Aquat Org 13:1-15

Findley AM, Blakeney EW Jr, Weidner EH (1981.) Ameson michaelis (Microsporidia) in the blue crab. Callnectes sapidus: parasite-induced alterations in the biochemical composition of host tissues. Biol Bull 161:115-125

Finney CM (1978) Isotopic labelling of taurine; implications for its synthesis in selected tissues of Homarus americanus. Comp Biochem Physiol 61B:409-413

Fossi MC, Savelli C, Casini S, Franchi E, Mattei N, Corsi I (1997) Multi-response biomarker approach in the crab Carcinus aestuarii experimentally exposed to benzo(a)pyrene, polychlorobiphenyls and methyl-mercury. Biomarkers 2:311-319

Henn MW, Schopf R, Maier WA, Seitz HM (1998) The amino 
acid composition of Anopheles stephensi (Diptera: Culicidae) infected with Nosema algerae (Microsporida: Nosematidae). J Invertebr Pathol 71:42-47

Johnson BR, Atema J (1986) Chemical stimulants for a component of feeding behaviour in the common gulf weed shrimp, Leander tenuicornis (Say). Biol Bull 170:1-10

Kuriyama K, Muramatsu M, Nakagawa K, Kakita K (1978) Modulating role of taurine on release of neurotransmitters and calcium transport in excitable tissues. In: Barbeau A. Huxtable RJ (eds) Taurine and neurological disorders. Raven Press, New York, p 201-216

Lin S, Cohen HP (1973) Crayfish ventral nerve chord and hemolymph: content of free amino acid and other metabolites. Comp Biochem Physiol 45B:249-263

Livingstone DR (1982) General biochemical indicators of sublethal stress. Mar Pollut Bull 13:261-263

Oja SS, Kontro P (1978) Neurotransmitter actions of taurine in the central nervous system. In: Barbeau A, Huxtable RJ (eds) Taurine and neurological disorders. Raven Press, New York, p 181-200

Payen GG, Pochon-Masson J, Portemer C, Chattanger F (1981) Effects of eyestalk ablation on the concentration of taurine in various organs of the shore crab Carcinus maenas (L.) (Decapoda: Brachyura). Comp Biochem Physiol 69A:571-574

Pequeux A, Vallota AC, Gilles R (1979) Blood proteins as related to osmoregulation in Crustacea. Comp Biochem Physiol 64A:433-435

Pochon-Masson J, Payen GG, Portemer C, Chattanger F (1984) Variations in taurine in the ovaries and hepatopancreas of the female crab Carcinus maenas L. (Decapoda: Brachyura) during the different phases of its genital activity. Int J Invertebr Reprod Dev 7:127-133

Robertson JD (1961) Studies on the chemical composition of muscle tissue. II. The abdominal flexor muscles of the lobster Nephrops norvegicus (L.). J Exp Biol 38:707-728

Robertson JD, Cowey CB, Leaf G (1992) The free amino acids in muscle of three marine invertebrates Nephrops nor-

Editorial responsibility: Timothy Flegel,

Bangkok, Thailand vegicus (L.), Limulus polyphemus (L.) and Eledone cirrhosa (Lamarck). Comp Biochem Physiol 101A:545-548

Stewart JE (1980) Diseases. In: Cobb JS, Phillips BF (eds) The biology and management of lobsters. Academic Press, New York, p 301-342

Taylor AC, Field RH, Parlow-Williams PJ (1996) The effects of Hematodinium sp.-infection on aspects of the respiratory physiology of the Norway lobster, Nephrops norvegicus (L.). J Exp Mar Biol Ecol 207:217-228

Thoroed SM, Fugelli K (1994) Free amino compounds and cell volume regulation in erythrocytes from different marine fish species under hypoosmotic conditions: the role of a taurine channel. J Comp Physiol 164B:1-10

van Marrewijk WJA, Ravenstein HJL (1974) Amino acid metabolism of Astacus leptodactylus Esch. I. Composition of the free and protein-bound amino acids in different organs of the crayfish. Comp Biochem Physiol 47B:531-542

Vivares CP, Cuq JL, Ceccaldi HJ, Richard PJ (1980) Influence d'une microsporidiose sur les acides aminés libres de Carcinus mediterraneus Czerniavsky, 1884 soumis à diverses salinitiés et à des valeurs extrêmes de température. J Exp Mar Biol Ecol 43:207-220

Voigt R, Wennemer $H$, Atema $J$ (1996) Spectral tuning properties of chemoreceptor cells in the front walking legs of the common spider crab Libinia emarginata. Mar Freshw Behav Physiol 27:261-267

Wang DI, Moeller FE (1970) Comparison of free amino acid composition in the haemolymph of healthy and Nosemainfected female honey bees. J Invertebr Pathol 15:202-206

Wong YM, Moore PG (1995) Biology of feeding in the scavenging isopod Natatolana borealis (Isopoda: Cirolanidae). Ophelia 3:181-196

Zatta P (1987) Calcium and taurine interaction in the heart of the crab Carcinus maenas. Can J Fish Aquat Sci 44: $1765-1768$

Zuo Z, Coombs GH (1995) Amino acid consumption by the parasitic amoeboid protists Entamoeba histolytica and $E$. invadens. FEMS Lett 130:253-258

Submitted: March 25, 1999; Accepted: June 21, 1999

Proofs received from author(s): October 18, 1999 